\title{
A design methodology and development of a mobile telepresence robot for paraplegics
}

\author{
Nasiru Adamu Marafa (D), Walter de Britto Vidal Filho (D), Carlos Humberto Llanos \\ Department of Mechanical Engineering, University of Brasilia - UnB, Brasilia, DF, Brazil \\ e-mails: marafanasir@ymail.com; wbritto@unb.br; llanos@unb.br
}

\begin{abstract}
Paraplegia is an impairment in motor or sensory function of the lower extremities. It is one of the conditions that exclude many people from the real society. Due to this limitation, many people have lost their jobs, some cannot take academic activities or participate in social events. In this scenario, the telepresence concept arises as an exciting field that includes virtual reality implementations, human-system interfaces, communication technologies, and robotics. In this direction, telepresence robots permit a virtual presence of persons in places where they are physically absent, such as in companies, lessons, and social events without the need to leave their homes. However, there is a gap in methodologies that can be applied in an appropriate way for their design and prototyping, that are addressed to help people with paraplegia. This paper describes a design methodology and development of a mobile telepresence robot for paraplegics. The design methodology introduced considers the mechatronic nature of the robotic devices. It can also be applied to similar projects development. It is systematic and follows a top-down approach, subdividing the mechatronic system problems into mechanical, electronic, and computational systems issues. In the mechanical system development, the robot's mechanical structure was developed and constructed, presenting the technical drawings of the robot's vertical structure and base. In electronic system development, an electronic command system was designed, which includes selection of sensors, motors, and a power board. In computational system development, an interaction between the user and the robot was designed to be established via the IP addresses of their individual locations. The results have shown to be promising to fill the lack of research in this essential specific area.
\end{abstract}

Keywords: robotics, product development, telepresence, paraplegics.

\section{Introduction}

The term telepresence was coined in an article published in the OMNI magazine, in June, 1980, by Marvin Minsky, cofounder of the Massachusetts Institute of Technology's Artificial Intelligence (AI) Laboratory. In the article, the concept of telepresence was described with a jacket, lined with sensors and muscles like motors, in such a way that, each motion of user's arm hand and fingers is reproduced at a distance place by mobile mechanical hands, thereby making it possible for the user to be able to work, not only in another place or another country, but also to be able to work in another planet, and without ever leaving home (Minsky, 1980). In this sense, Telepresence robots can be described as robots that permit a virtual presence of persons in places where they are physically absent.

With advances in robotics, video conferencing technologies, and human-system interfaces, the concept of telepresence arises as an exciting field that integrates virtual reality implementations with human-system interfaces, robotics, and communication technologies. In recent years, several attempts were made in the literature to design and develop mobile telepresence robots for various applications, such as for: paraplegics, academic, medical assistance, factory inspection, among others. However, other scenarios of applications, features, that telepresence robots must incorporate for use in ad-hoc interactions, and who benefits from using these robotic devices are discussed in Tsui et al. (2011).

A motor disability is defined as a physical or motor dysfunction that can impede movement, coordination or sensation, which may be congenital or acquired. The acquired forms are mostly caused by traffic accidents, accidents at work places, medical errors, war, violence, malnutrition, among others. Some of the types of motor disabilities are: monoplegia (paralysis of only one body member), hemiplegia (paralysis of half of the body), paraplegia (paralysis from the waist down), tetraplegia (paralysis from the neck down), and amputation (missing a body member). In this work, the main focus is paraplegia. However, applications can also extend to hemiplegia, monoplegia and amputation, where the user is considered to have movements at his hands. The required 
movements at the user's hands are to enable him/her navigate the robot using an interface on computer or tablet. Also in this work, the target users of the final product are considered to be Brazilians.

The number of paraplegics is increasing worldwide. For instance, in the United States of America alone, there were approximately 5.6 million paraplegics in 2019, which was equivalent to $1.9 \%$ of the total US's population in that year (Christopher \& Dana Reeve Foundation, 2019). In Brazil, in 2018 , about $6.7 \%$ of the Brazilian population showed some type of disability (Lailla et al., 2018), and it is our belief that, a big part of this population consists of paraplegic patients. Due to this limitation, many people have lost their jobs, while some cannot take lessons from their schools, and some cannot even participate in social events. In this sense, a motor disability can be considered as one of the conditions that exclude many people from the real society.

In order to provide a tool to free these people to the outside world, and to provide them a means by which they can work, participate in lessons or social events, without the need to leave their homes, a low cost mobile telepresence robot is proposed and developed through a created design methodology which facilitates its development and reduces its production cost. The methodology considers the mechatronic nature of a problem in question, and systematically subdivides the mechatronic system into three sub systems, which are: mechanical, electronic, and computational systems. Each system is developed individually, and integrated together to form a single mechatronic system.

In the mechanical system development phase, the robot's mechanical structure was developed and constructed, presenting the technical drawings of the robot's vertical structure and base. In the electronic system development phase, an electronic command system was designed, which includes, selection of sensors, motors, and a power board. While in the computational system development phase, an interaction between the user and the robot was designed to be established via the IP addresses of their individual locations by using a computer or tablet. In this case, two programs in HTML (HyperText Markup Language) were developed, a user program and a robot program. Java codes were integrated into the two programs permitting a video conference between the two sides. Another java code was integrated only into the user program for the robot navigation control.

\section{Design methodology}

In this work, a sequence of steps was created for the proposed design methodology, which are: (a) Problem definition and Keyword selection, (b) Literature review analysis, (c) Project requirements, (d) Mechatronic system development, (e) Prototype construction (f) Solution testing, and (g) Results communication. The six possible ways for this sequence of steps are shown in Figure 1.

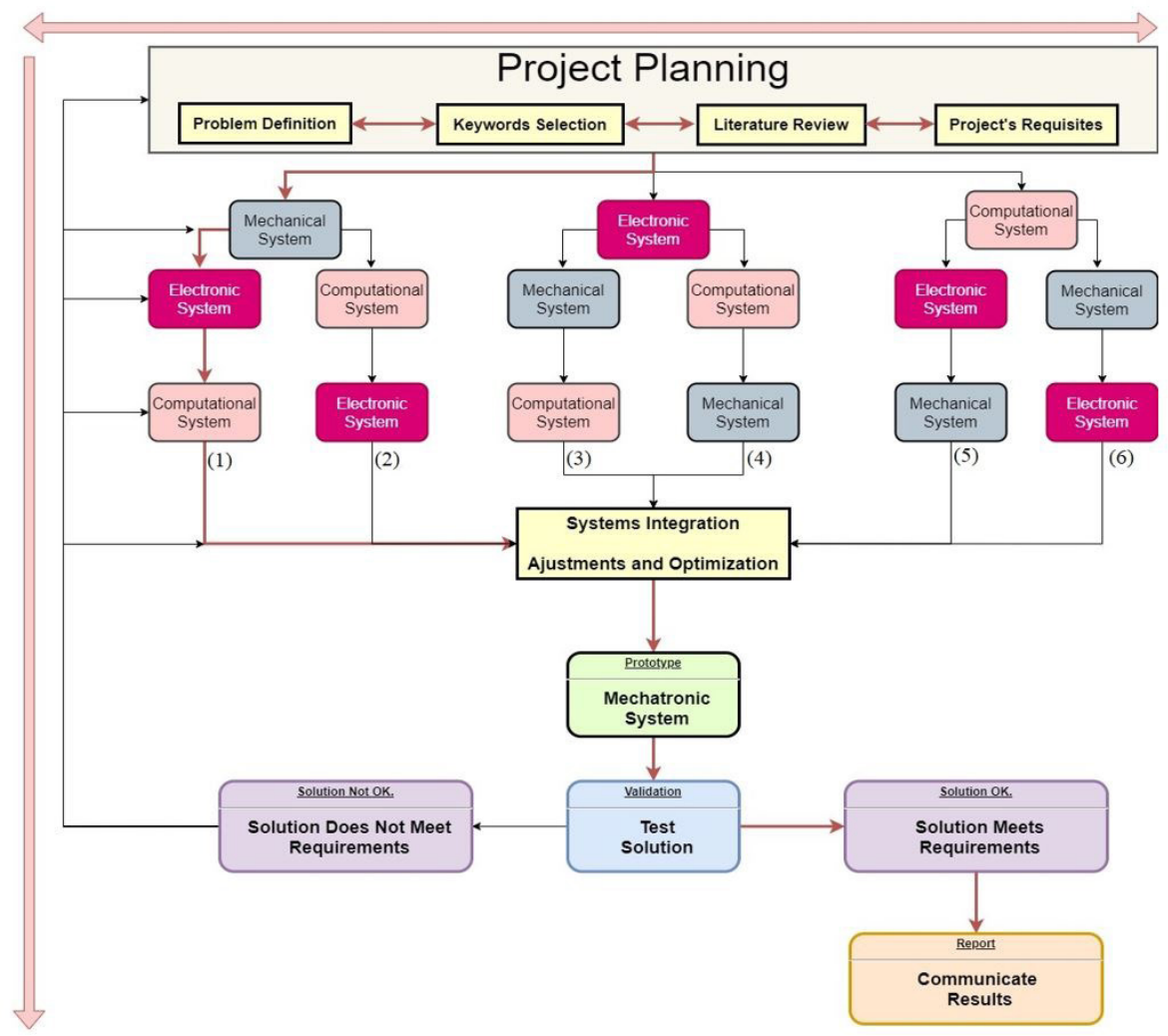

Figure 1. The Six Possible Sequences for the Design Methodology. Source: Author. 
For this work, the first sequence, indicated by the pink colored arrows was selected, and it strictly follows these steps: Problem definition and Keyword selection $\rightarrow$ Literature review analysis $\rightarrow$ Project requirements $\rightarrow$ Mechanical system development $\rightarrow$ Electronic system development $\rightarrow$ Computational system development $\rightarrow$ Prototype construction $\rightarrow$ Solution testing $\rightarrow$ Results communication.

In the mechatronic system development phase, the mechanical system was developed first, then the electronic system and finally the computational system. The advantage of this arrangement is that, for the majority of mechatronic systems, there is the need for system identification before the control system is developed. Through this process, the mathematical models of the dynamic systems are built by using measurement of the system's input and output signals. This input and output measurement can only be measured from the mechanical and electronic systems already developed. However, in this work, the aim for selecting to start with the mechanical system design is to facilitate a proper dimensioning of motors, since the required torque in the electronics system depends on mechanical system's properties, such as, the structural weight, inertia and friction.

\section{Problem definition and keywords selection}

In the Problem definition and Keywords selection phase of the design methodology, the problem to be investigated was defined, and adequate keywords were selected for document search from accredited scientific databases that are related to the topic in question. Therefore, for this work, the problem was defined as "design and develop a low cost mobile telepresence robot for paraplegics, for the Brazilian population".

After the problem was defined, there was the need to select some adequate keywords from the defined problem for the literature review analysis. In these case, four keywords were selected and used for searching documents, these keywords are: telepresence, robotic, design and paraplegic.

\section{Literature review analysis}

In the literature review analysis phase of the design methodology, telepresence robots manufactured by some companies around the world for commercial gains were analyzed, and relevant projects in the academic field that are related to the topic, which are already published in the literature and that can be found in accredited databases are analyzed. Therefore, the Literature review analysis was carried out on two main axes: (a) Commercial products, which involves the analysis of the telepresence robots available in the markets for commercial gains, and (b) Academic publications, which involves the use of the selected keywords to explore academic publications available in some selected and accredited databases. The relevant projects considered include: articles, books, theses and dissertations. Also in this phase, a bibliometric analysis was also performed. This is to further analyze the relationship between the collected documents and their authors. To achieve this, a bibliographic coupling and keywords co-occurrence analyses were performed.

\subsection{Commercial products}

In recent years, there are many different companies around the world investing in telepresence robotics for various applications. These investments are resulting in many products in the international markets for commercial gains. Some of the investigated telepresence robots found in the markets include: Beam Plus, Double 2, PadBot U1 v.2, TeleMe 2 and VGo (Figure 2). These robots were further analyzed and Table 1 presents some of the observed characteristics, such as: heights, weights, wheels type, number of wheels, maximum attainable speeds, video conference screen sizes, battery durability and prices. Besides being very similar in their physical structures and adopted technologies, it was also observed that, there are many differences from one project to another.

\subsection{Academic publications}

In the literature review on academic publications, the selected keywords were used to search for relevant documents from five selected and accredited databases. They are: (1) Web of Science, (2) Scopus, (3) IEEE Xplore, (4) Catalog of Theses and Dissertations (CTD) maintained by National Council for Scientific and Technological
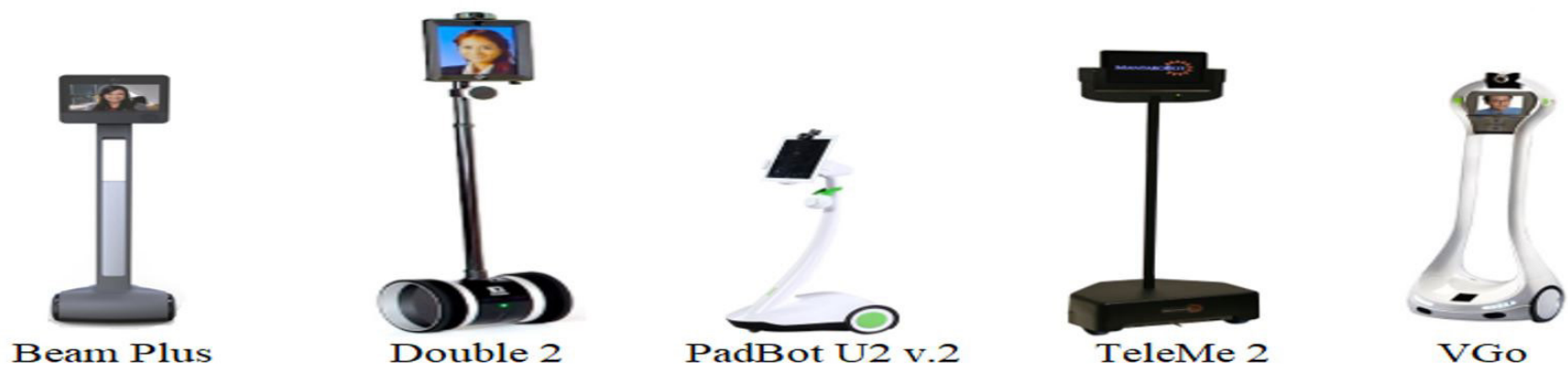

Figure 2. Mobile Telepresence Robot in Markets (Robots, 2020). 
Development (CAPES) and (5) Digital Library of Theses and Dissertations (BDTD) maintained by the Brazilian Institute of Information in Science and Technology (IBICT).

By using the constructed string ("Telepresence" AND "Robot" AND ("Design" OR "Project" OR "Development" OR "Modeling")) to search for relevant documents from all the selected databases. Table 2 shows: the search type, number of documents, and the first year of publication in each database, in brackets ( $\mathrm{x}$ ) is the number of documents published in the first year of publication in a database. It is important to make it clear at this point that, the results presented in Table 2 were obtained on 02 February 2020, and they might increase with time as the number of publications increases in these databases.

Furthermore, results from databases, Web of science (281 documents) and Scopus (534 documents) were further analyzed, presenting the best 'top 5': (a) most prominent research areas, (b) most highlighted research countries, (c) sources with the highest register of documents, (d) most cited documents and (e) journals with the highest number of publications, (Table 3, 4, 5, 6 and 7). In the Bibliometric analysis, VOSviewer tool was used for a Bibliographic

Table 1. Telepresence Robot Properties Comparison in the Market.

\begin{tabular}{|c|c|c|c|c|c|}
\hline & Beam Plus & Double2 & PadBotU1 v.2 & TeleMe 2 & Vgo \\
\hline Height $(\mathrm{cm})$ & 134.4 & $120-150$ & 87.6 & - & 121.92 \\
\hline Screen & Tablet & Tablet & Tablet & Tablet & Tablet \\
\hline Video Resolution (HDR) & $640 \times 480$ & Depends & Depends & Depends & $320 \times 240$ \\
\hline Maximum Velocity (km/h) & 1.45 & - & 2.64 & 2.25 & 3.29 \\
\hline Battery & 2 horas & $6-8$ horas & 10 horas & 8 horas & 6 horas \\
\hline Price (US \$) & $2,140.00$ & $2,749.00$ & 797.00 & - & $3,995.00$ \\
\hline
\end{tabular}

Table 2. Results for the three Constructed Strings Obtained from the Selected Databases.

\begin{tabular}{|c|c|c|c|}
\hline Database & Search Type & Results & $\mathbf{1}^{\mathbf{0}}$ Year Publication \\
\hline Web of Science & Topic & 281 & $1992(1)$ \\
\hline Scopus & Title, Abstract, Keywords & 534 & $1985(2)$ \\
\hline IEEE & All & 243 & $1986(1)$ \\
\hline CTD & All & 3 & $1999(1)$ \\
\hline BDTD & All & 4 & $1998(1)$ \\
\hline
\end{tabular}

Table 3. The Most Prominent Research Areas from Web-of-Science and Scopus.

\begin{tabular}{|c|c|c|c|c|c|}
\hline \multicolumn{2}{|c}{ Web of Science } & \multicolumn{2}{c|}{ Scopus } \\
\hline Subject Ares & Result & \% of 281 & Subject Area & 353 & \% of 534 \\
\hline Robotics & 122 & 43.42 & Computer Science & 66.10 & 519 \\
\hline Engineering & 117 & 41.64 & Engineering & 88 & 16.74 \\
\hline Computer Science & 116 & 41.28 & Mathematics & 54 & 10.11 \\
\hline Automation Control Systems & 55 & 19.57 & Medicine & 39 & \\
\hline Optics & 10 & 3.56 & Physics and Astronomy & 3.30 \\
\hline
\end{tabular}

Table 4. The Most Highlighted Research Countries from Web-of-Science and Scopus.

\begin{tabular}{|c|c|c|c|c|c|}
\hline \multicolumn{2}{|c}{ Web of Science } & \multicolumn{2}{c|}{ Scopus } \\
\hline Country & Result & \% of 281 & Country & Result & \% of 534 \\
\hline United State & 70 & 24.91 & United State & 53 & 26.40 \\
\hline Japan & 35 & 12.45 & Japan & 42 & 9.92 \\
\hline Germany & 27 & 9.61 & Germany & 4.86 & 7.49 \\
\hline Italy & 23 & 8.18 & Peoples R. China & 40 & \\
\hline Canada & 20 & 7.12 & Canada & 38 & \\
\hline
\end{tabular}

Table 5. Sources with the Highest Register of Documents from Web-of-Science and Scopus.

\begin{tabular}{|l|c|l|c|}
\hline \multicolumn{1}{|c|}{ Seb Of Science } & \multicolumn{1}{c|}{ Scopus } \\
\hline \multicolumn{1}{|c|}{ Source Title } & Register & \multicolumn{1}{c|}{ Reurce Title } \\
\hline $\begin{array}{l}\text { ACM IEEE International Conference on Human Robot } \\
\text { Interaction. }\end{array}$ & 11 & $\begin{array}{l}\text { Proceedings of SPIE: The International Society for Optical } \\
\text { Engineering. }\end{array}$ & 26 \\
\hline $\begin{array}{l}\text { IEEE International Conference on Robotics and } \\
\text { Automation ICRA }\end{array}$ & 11 & $\begin{array}{l}\text { Lecture Notes in Computer Science Including Subseries Lecture } \\
\text { Notes in Artificial intelligence and Lecture Notes in Bioinformatics. }\end{array}$ & 21 \\
\hline Lecture Notes in Computer Science & 7 & ACM IEEE International Conference on Human Robot Interaction. & 16 \\
\hline $\begin{array}{l}\text { Proceedings of the Society of Photo Optical } \\
\text { Instrumentation Engineers SPIE }\end{array}$ & 7 & Conference on Human Factors in Computing Systems Proceedings & 15 \\
\hline IEEE RO MAN & 6 & $\begin{array}{l}\text { Proceedings IEEE International Conference on Robotics and } \\
\text { Automation. }\end{array}$ & 14 \\
\hline
\end{tabular}


Table 6. The Most Cited Documents from Web-of-Science.

\begin{tabular}{|l|c|c|c|}
\hline \multicolumn{1}{|c|}{ Title } & Author/Year & Citations & Comment/Status \\
\hline Stability and Transparency in Bilateral Teleoperation & Lawrence (1993) & 1195 & R/I \\
\hline $\begin{array}{l}\text { RGB-D Mapping: Using kinetic-style depth cameras for dense 3D modeling } \\
\text { of indoor environment }\end{array}$ & Henry et al. (2012) & 576 & R/I \\
\hline $\begin{array}{l}\text { Robotic surgery, telerobotic surgery, telepresence, and telementoring - review } \\
\text { of early clinical results }\end{array}$ & Ballantyne (2002) & 343 & \\
\hline Experiences with an interactive museum tour-guide robot & Burgard et al. (1999) & 280 & R/I \\
\hline A steady-hand robotic system for microsurgical augmentation & Taylor et al. (1999) & 261 & R/I \\
\hline
\end{tabular}

Table 7. The Most Cited Documents from Scopus.

\begin{tabular}{|l|c|c|c|}
\hline \multicolumn{1}{|c|}{ Title } & Author/Year & Citations & $\begin{array}{c}\text { Comment/ } \\
\text { Status }\end{array}$ \\
\hline Stability and Transparency in Bilateral Teleoperation & Lawrence (1993) & 1558 & R/I \\
\hline $\begin{array}{l}\text { RGB-D Mapping: Using kinetic-style depth cameras for dense 3D modeling } \\
\text { of indoor environment }\end{array}$ & Henry et al. (2012) & 775 & R/I \\
\hline Experiences with an interactive museum tour-guide robot & Burgard et al. (1999) & 482 & R/I \\
\hline $\begin{array}{l}\text { Robotic surgery, telerobotic surgery, telepresence, and telementoring - review } \\
\text { of early clinical results }\end{array}$ & Ballantyne (2002) & 441 & R/I \\
\hline Telepresence & Draper et al. (1998) & 210 & R/I \\
\hline
\end{tabular}

coupling analysis while TagCrowd was used for the Keywords Co-occurrence analysis.

\subsection{Bibliometric analysis}

\subsubsection{Bibliographic coupling (documents)}

The Bibliographic coupling using VOSviewer relates the number of cited references that two publications have in common. In this case, the bigger the circle of a document, the stronger the citation. Therefore, for Web of Science, the minimum number of citations of document was set to 3 and of 281 documents, 113 meet the thresholds (Figure 3). While for Scopus, the minimum number of citations of document was set to 3, and in this case, of 534 documents, 244 meet the thresholds (Figure 4). Therefore, from both the two databases, Web of Science and Scopus, Lawrence (1993) was observed to be the most cited document.

\subsubsection{Co-occurrence analysis ( TagCrowd)}

The Keyword Co-occurrence analysis using TagCrowd relates the occurrence of a keyword in two or more documents. In this case, the bigger the appearance of a keyword, the higher the number of documents it is repeated. In Figure 5 and Figure 6, TagCrowd tool was used to analyze this relationship, by using the Web of Science's and Scopus's data, collected from the search result in Table 2. The keyword Robot appears in more documents than any other keyword in both the Web of Science's and Scopus's documents, therefore, it appears bigger and more visible.

Analyzing further what was done in the academic field, it was observed in Do et al. (2013) the use of ROS (Robot Operating System) and a tablet in a mobile telepresence robot. An android app for the tablet was created (based on rosjava_core and android_core) for the control and a live video streaming between the user and the robot. In Carranza et al. (2019), a mobile telepresence robot was designed for medical consultation, where the robot chassis was made from galvanized steel bars, and the joints were connected using bolts and nuts. In Hijazi \& Al-Khatib (2016), it was demonstrated that, a telepresence robot can be designed and controlled via the internet using Raspberry pi and Arduino microcontroller. To facilitate client-server video-audio communication, a tablet was adopted as the screen, and by using communication platforms such as Skype, among others.

Furthermore, Rodrigues et al. (2015) showed that, a telepresence robot can be developed using a methodology that subdivides the project into three subparts, a mechanical part, an electronic part and a computational part. Each part is developed separately and integrated together to form a single system. This is adapted methodology with some modifications as mentioned in section 2. It was observed from the literature review that, there are several solutions available for the motor control, teleoperation, construction

Table 8. Observed Parameters from the literature.

\begin{tabular}{|l|c|}
\hline \multicolumn{1}{|c|}{ Robot's Parameters } & Observed Variations \\
\hline Number of Wheels & 2 or 3 or 4 wheels \\
\hline Velocity & $2.2 \mathrm{~km} / \mathrm{h}-5.5 \mathrm{~km} / \mathrm{h}$ \\
\hline Weight & $8.0-43.0 \mathrm{Kg}$ \\
\hline Battery Autonomy & $4-12 \mathrm{~h}$ \\
\hline Height & $0.876-1.88 \mathrm{~m}$ \\
\hline Number of Cameras & $1-2$ \\
\hline Camera Resolution & 3 mega pixel $-14 \mathrm{mp}$ \\
\hline Screen Size & $3.5^{\prime}$ Diagonal (Minimum) \\
\hline Navigation Control & Keyboard - Mouse \\
\hline
\end{tabular}




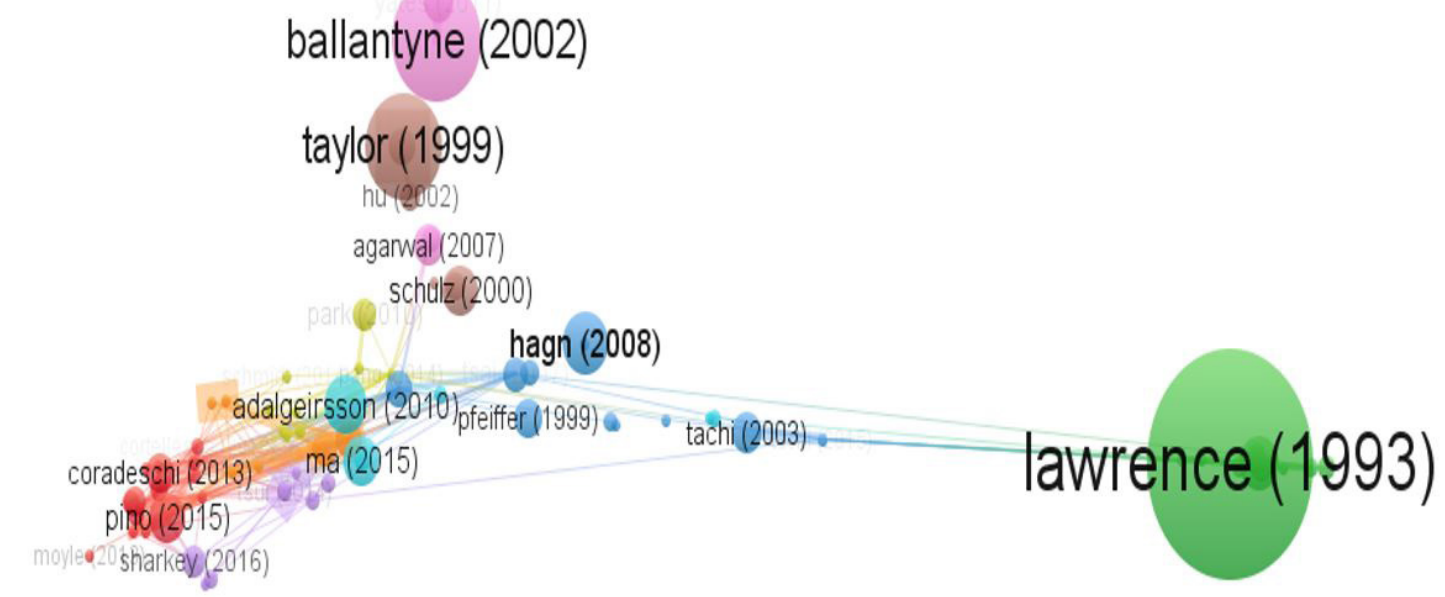

Figure 3. Bibliographic Coupling Web of Science.

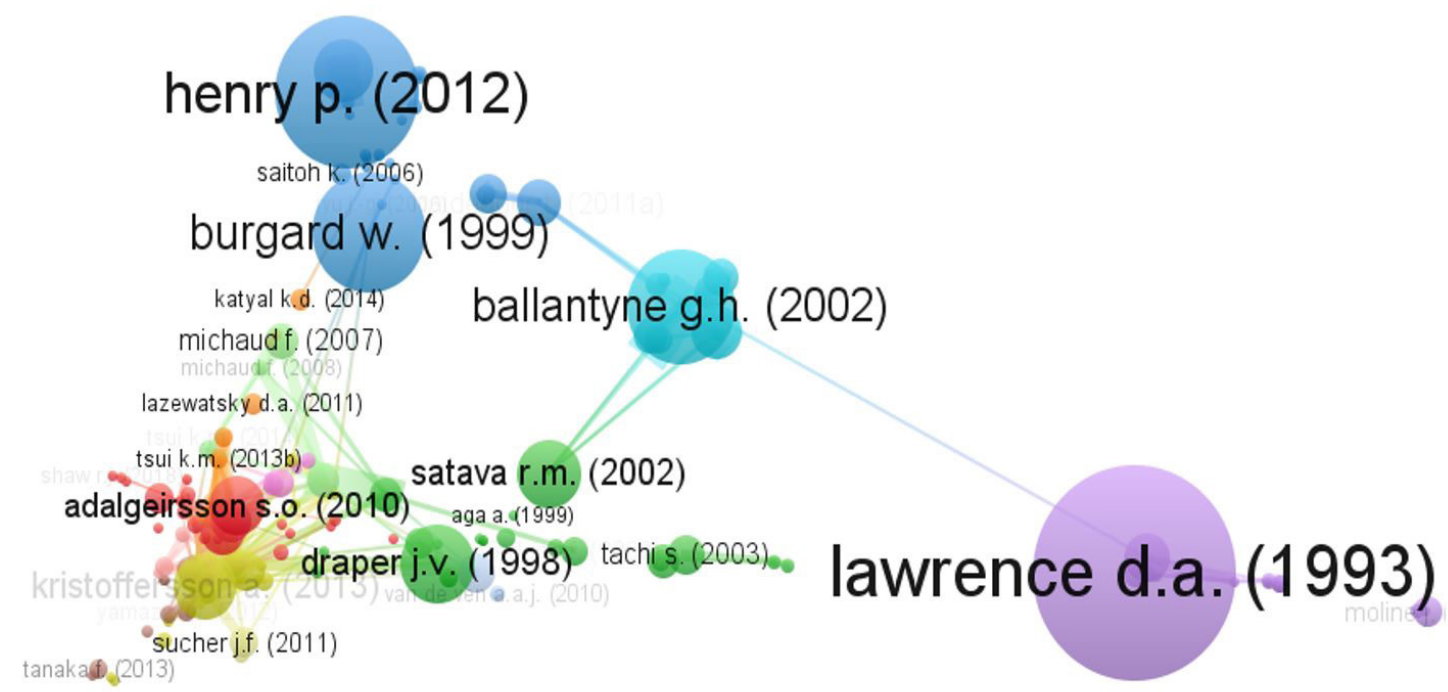

Figure 4. Bibliographic Coupling Scopus.

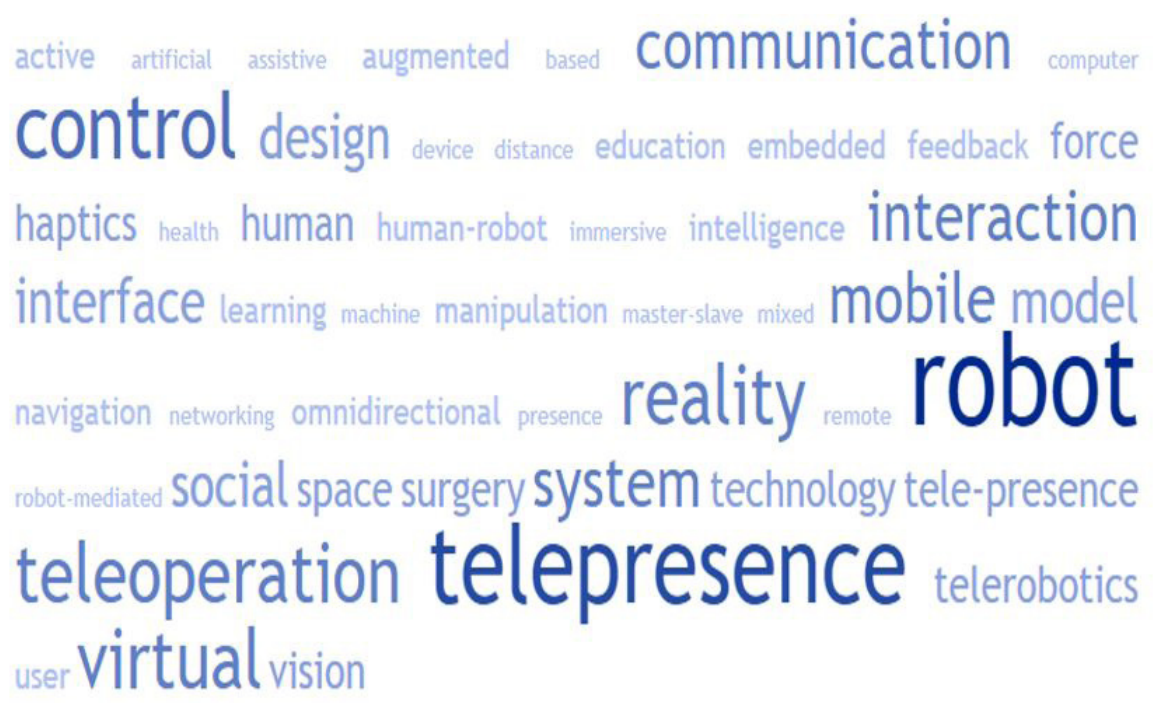

Figure 5. Co-occurrence of keywords Web of Science. 


\section{active assistive augmented avatar care communication computing control design derice distance education embodied feedback force haptic health human human-robot humanoid intelligent interaction interface

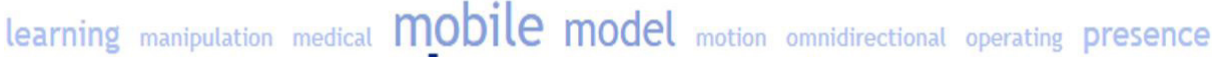

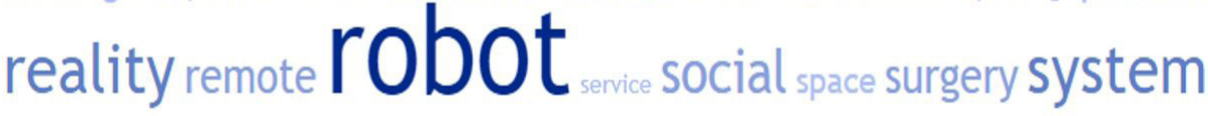 technology resence}

Figure 6. Co-occurrence of keywords Scopus.

of vertical structure and base of the robot. Some variations observed in the projects analyzed from the literature are presented in Table 8.

\section{Project requirements}

In Project requirements phase, the project requirements and parameters were established. In this case, some of the selected documents were used as the basis for establishing the requirements. It is important to make sure that, the requirements established satisfy the basic project's requisites before passing to the next phase, as doing this minimizes unprecedented errors.

To establish a standard height for the robot that is compatible with the target population's height, the average height of Brazilians analyzed by the IBGE in 2009, was used (Instituto Brasileiro de Geografia e Estatistica, 2009), according to this analysis, the average height was $1.73 \mathrm{~m}$ among men and $1.60 \mathrm{~m}$ among women. To determine the speed requirements of the robot, the study made by Novaes et al. (2011) was used, this study showed that, the average gait speed of Brazilians over 40 years old was $1.26 \mathrm{~m} / \mathrm{s}$ among men and $1.16 \mathrm{~m} / \mathrm{s}$ among women. Threewheel configuration was chosen instead of four in order to facilitate the robot's maneuverability and control. In this sense, only two wheels are motorized and controlled, while one wheel is free to facilitate the robot's spin control, which reduces the production cost. Autonomy was chosen by market analysis (Table 9).

\section{Mechatronic system development}

In the Mechatronic system development phase, the mechatronic system was subdivided into three components: (a) Mechanical system development. In this part, technical drawing of the robot's base and vertical structure, calculation of mechanical stability, and 3D drawing of the mechanical components were conducted; (b) Electronic
Table 9. Parameters and Project's Requirements.

\begin{tabular}{|c|c|}
\hline Selected Parameters & Requisites \\
\hline Number of Wheels & 3 Wheels \\
\hline Number of controlled Wheels & 2 Wheels (Front) \\
\hline Operational Max. Velocity & $2.5 \mathrm{~km} / \mathrm{h}$ \\
\hline Robot's Total Height & $1.50-1.60 \mathrm{~m}$ (Adjust. $10 \mathrm{~cm})$ \\
\hline Total Weight & $12 \mathrm{~kg}$ \\
\hline Battery Autonomy & $12 \mathrm{~h}$ \\
\hline Traction Type & Differential \\
\hline Maximum Inclination & $20^{\circ}$ \\
\hline
\end{tabular}

system development. In this part, electronic command circuit was designed, motor dimensioning, calculations of minimum required motor power, angular velocity and torque were conducted; and (c) Computational system development. In this part, two programs were developed, a user program which runs on a computer or tablet as an interface, and a robot program which runs on the robot scree (tablet). The user program incorporates a videoconferencing technology and a robot navigation controller.

\subsection{Mechanical system development}

\subsubsection{Technical drawings}

In this part, the mechanical structure of the robot was designed using a computer aided design software (CAD). The dimensions of the robot's mechanical structure and base are shown in Figure 7 and Figure 8 respectively. The vertical stand is adjustable from $150 \mathrm{~cm}$ to $160 \mathrm{~cm}$. this allows the use of the robot for different heights. The use of CAD tools is to facilitate redrawing of parts, enables solid modeling, generate a 3D model for analysis.

\subsubsection{Calculation of mechanical stability}

To ensure the stability against tipping of the robot, the center of gravity (CG) was calculated using Equation 1. With this, the minimum width for stability was determined. 


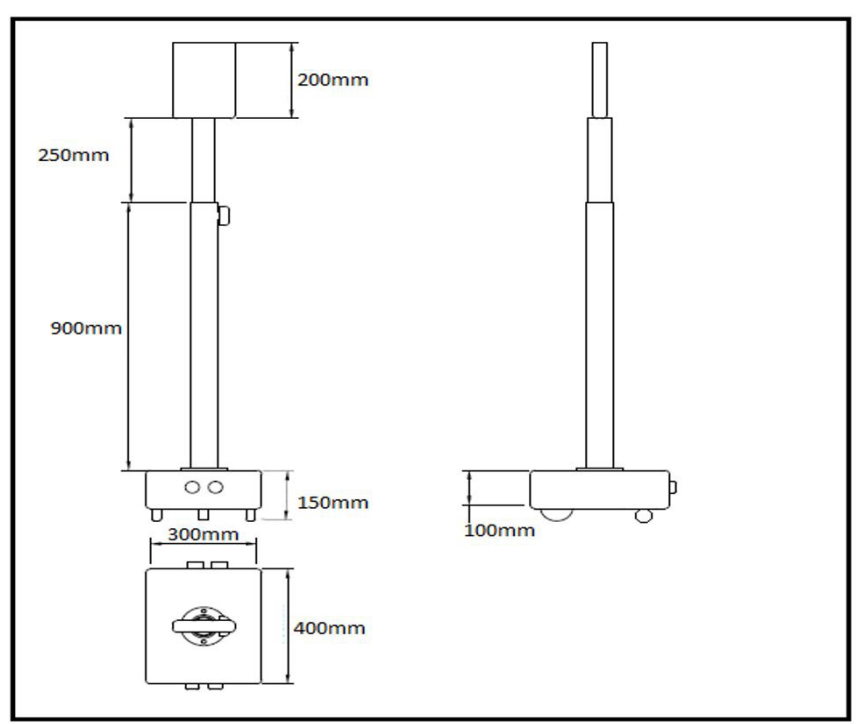

Figure 7. Technical Design of the Robot.

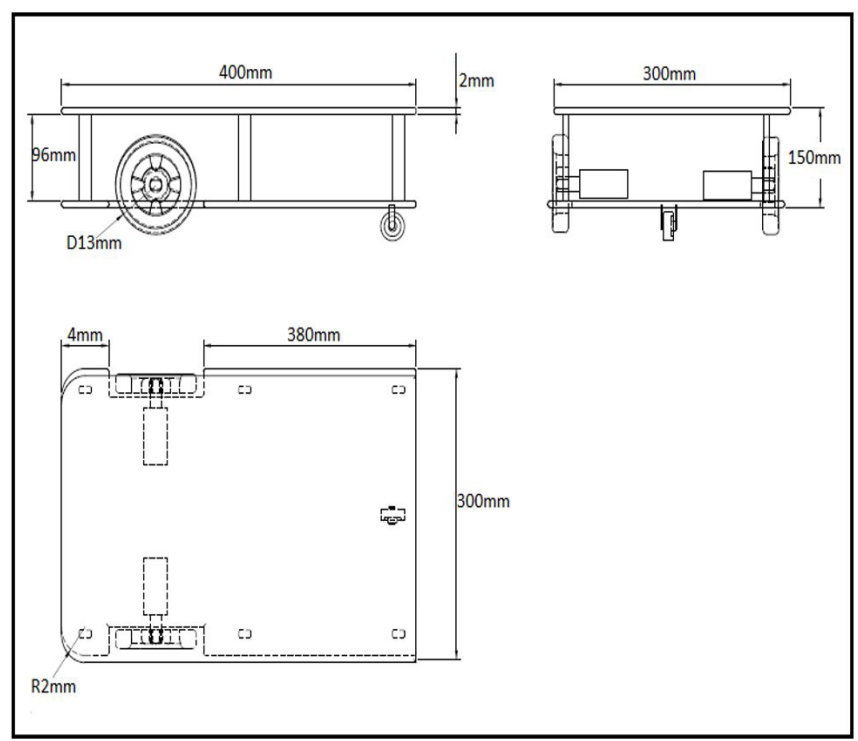

Figure 8. Technical Design of the Base.

To calculate the CG of the robot, the adapted weights of the vertical structural components were established according to Table 10, and their distances from a reference point is shown in Figure 9.

$$
\mathrm{Y}_{\mathrm{CG}}=\frac{\mathrm{mly} 1+\mathrm{m} 2 \mathrm{y} 2+\mathrm{m} 3 \mathrm{y} 3+\mathrm{m} 4 \mathrm{y} 4}{\mathrm{mt}}
$$

$\mathrm{m} 1$ is the base mass $=10 \mathrm{~kg}$, with $\mathrm{y} 1=75 \mathrm{~mm}, \mathrm{~m} 2$ is the outer vertical support mass $=1.0503 \mathrm{~kg}$, with $\mathrm{y} 2=600 \mathrm{~mm}, \mathrm{~m} 3$ is the inner vertical support mass $=0.348 \mathrm{~kg}$, and $\mathrm{y} 3=1225 \mathrm{~mm}$, $\mathrm{m} 4$ is tablet mass $=0.45 \mathrm{~kg}$, and $\mathrm{y} 4=1500 \mathrm{~mm}$, finally, $\mathrm{mt}$ is the total maximum mass of the robot, which was set to $12 \mathrm{~kg}$.

$$
\mathrm{Y}_{\mathrm{CG}}=\frac{10(0.075)+1.0503(0.6)+0.348(1.225)+0.45(1.5)}{12}
$$

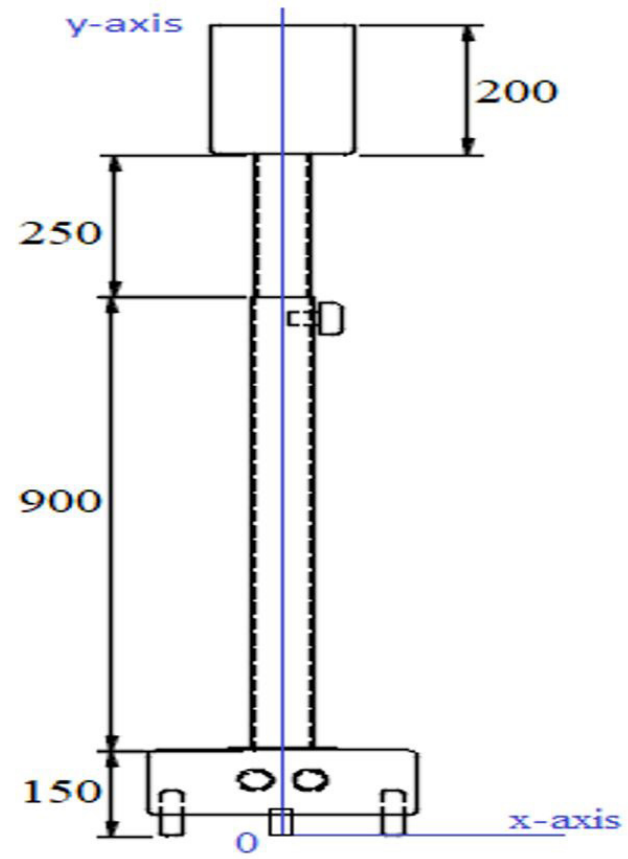

Figure 9. Reference for Mass Center Calculation.

Table 10. Weight of the Robot's Components.

\begin{tabular}{|c|c|c|c|}
\hline Structure & Dimensions $(\mathrm{mm})$ & Weight & $\begin{array}{c}\text { Adapted } \\
\text { Weight }(\mathrm{kg})\end{array}$ \\
\hline \multirow{2}{*}{$\begin{array}{c}\text { Samsung } \\
\text { Tab2 }\end{array}$} & $193.7 \times 122.4 \times 10.5$ & $0.345 \mathrm{~kg}$ & \multirow{2}{*}{0.450} \\
\cline { 2 - 3 } Tube & $166.8 \times 242.5 \times 7.5$ & $0.450 \mathrm{~kg}$ & \\
\cline { 2 - 3 } & $\mathrm{D} 42.20 \times 3.56$ & $1.167 \mathrm{~kg} / \mathrm{m}$ & \multirow{2}{*}{1.05030 .348} \\
\hline Base (Set) & $400 \times 33.40 \times 3.38$ & $0.870 \mathrm{~kg} / \mathrm{m}$ & 10 \\
\hline
\end{tabular}

$\mathrm{Y}_{\mathrm{CG}}=\frac{2.48148}{12}=0.20679 \mathrm{~m}=206.79 \mathrm{~mm}$ and $\mathrm{X}_{\mathrm{CG}}=0 \mathrm{~mm}$

Then, to calculate the smallest base that has stability against tipping, considering a ramp of $20^{\circ}$. If the base length of the robot is $\mathrm{L}$, then:

$$
\begin{aligned}
& \frac{\mathrm{L}}{2}=\tan 20 \times(206.79-150)=20.7 \mathrm{~mm} \\
& \mathrm{~L}=2 \times 20.7 \mathrm{~mm}=41.34 \mathrm{~mm}
\end{aligned}
$$

\subsubsection{D drawing}

The 3D modeling was made to visualize the appearance of the robot to be manufactured. Figure 10 shows the vertical structure of the robot while Figure 11 shows the robot's base.

\subsection{Electronic system development}

\subsubsection{Dataflow of the electronic system}

To develop the electronics circuit, some components were used, which are: one $12 \mathrm{v}$ battery to power the whole system, one switch, two DC motors, two encoders for 
motor speed control, one H-Bridge plates for motor's speed and direction control, one Arduino Uno micro-controller, one $12 \mathrm{v}-5 \mathrm{v}$ voltage divider to power the Arduino, whose operating voltage is $5 \mathrm{v}$, two ultrasonic sensors (one front and one rear) to detect obstacles on the robot's path in order to avoiding collisions, a WiFi module to connect the Arduino

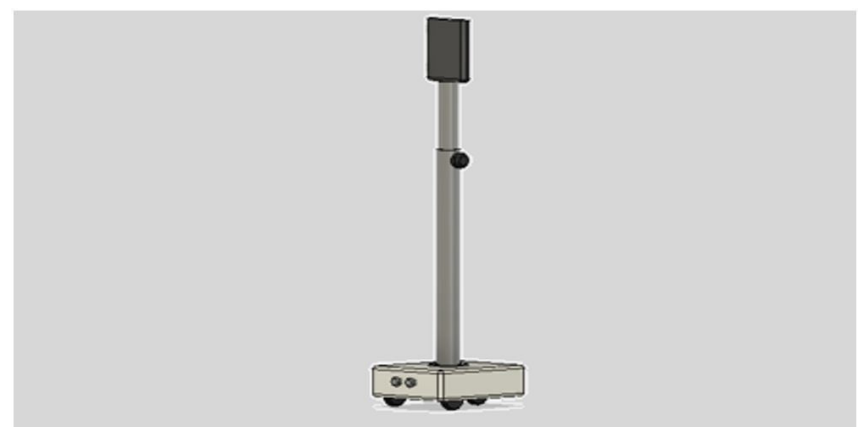

Figure 10. 3D Design of the Robot.

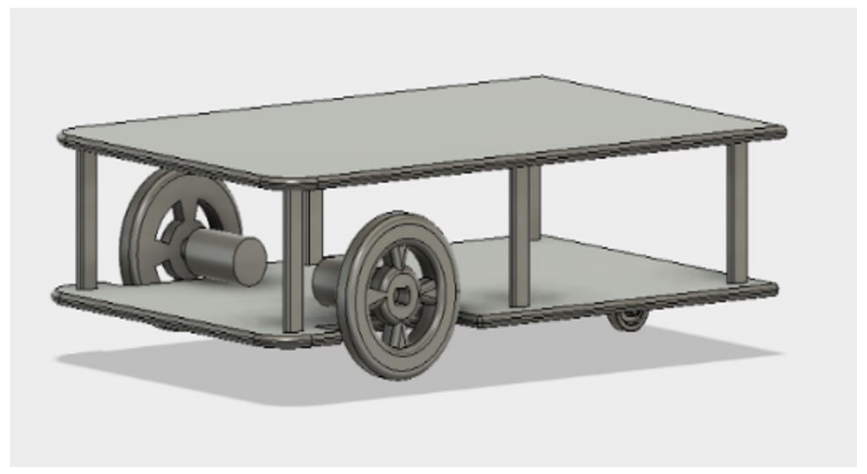

Figure 11. 3D Design of the Robot's Base. to the internet (server) which enables a serial communication between the robot and the user. The user accesses the server via the network and establishes communication between them through their IP addresses. Figure 12 shows the data flow between electronic components.

\subsubsection{Robot force calculation}

To select motors, it was necessary to calculate the torque, speed and power required to move the robot, considering the robot's ability to overcome a $20^{\circ}$ incline ramp. Therefore, to calculate the rolling friction $\mathrm{F}_{\mathrm{R}}$, Equation 2 was used.

$$
\begin{aligned}
& \mathrm{F}_{\mathrm{R}}=\mu_{\mathrm{R}} \cdot \mathrm{N} \\
& \mathrm{F}_{\mathrm{R}}=\mu_{\mathrm{R}} \times \mathrm{N}=0.015(12 \times 10)=1.8 \mathrm{~N}
\end{aligned}
$$

Calculating for $\theta=20^{\circ}$, Equation 3 was used.

$$
\begin{aligned}
& \mathrm{F}_{1}=\mathrm{W} \times \operatorname{sen} \theta \\
& \mathrm{F}_{1}=12 \times 10 \times \operatorname{sen} 20=68.4 \mathrm{~N}
\end{aligned}
$$

To calculate external forces by raising the rolling friction slope, Equation 4 was used.

$$
\begin{aligned}
& F=W\left(\mu_{R} \times \cos \theta+\operatorname{sen} \theta\right) \\
& F=12 \times 10(0.015 \times \cos 20+\operatorname{sen} 20)=42.7 N
\end{aligned}
$$

Rolling friction ground Level:

$$
\mathrm{F}=\mu_{\mathrm{R}} \times \mathrm{W}=0.015 \times 12 \times 10=1.8 \mathrm{~N}
$$

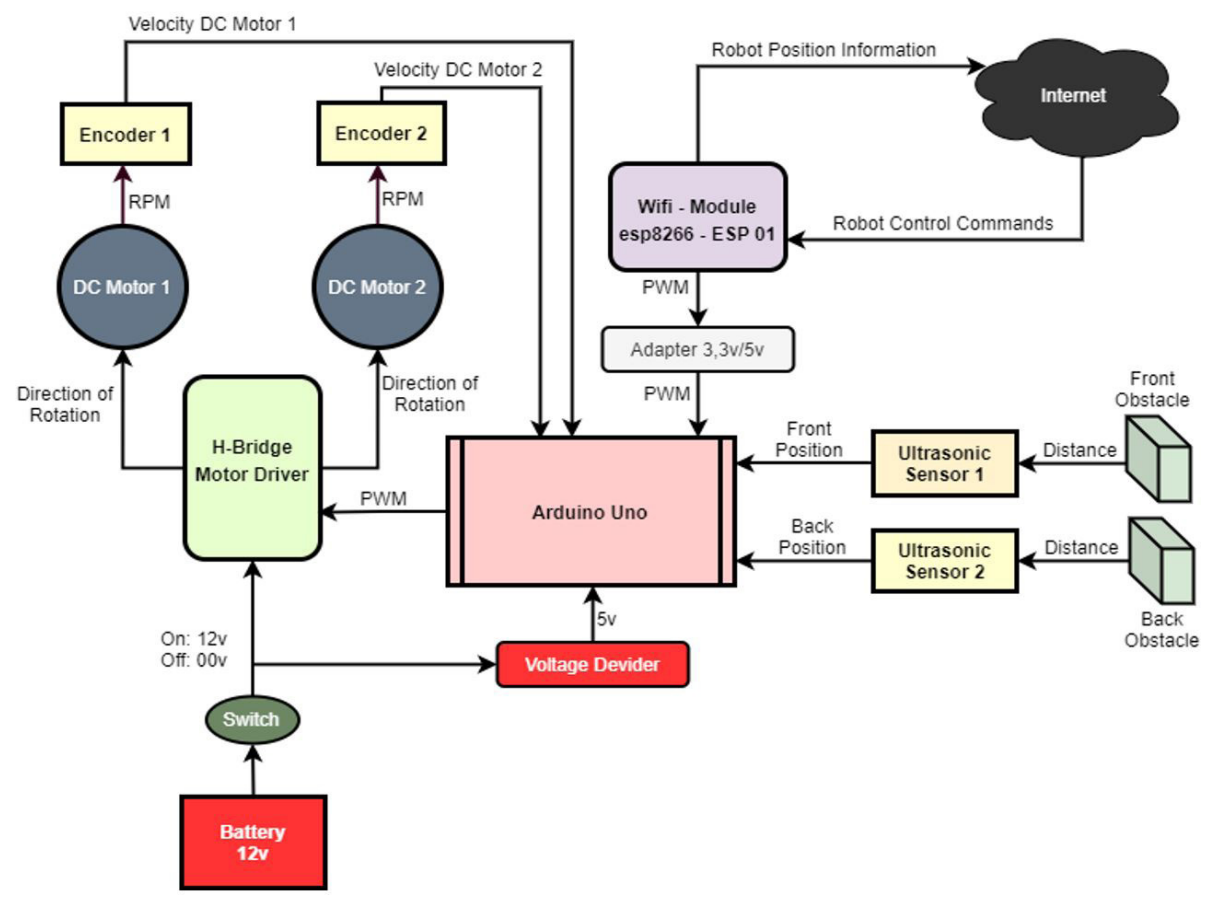

Figure 12. Dataflow of the Electronic Component. Source: Author. 


\subsubsection{Motor power calculation}

To determine the maximum speed $\mathrm{V}$ that the robot moves with the maximum load going up the slope, it was established that, the robot had to travel at a maximum speed of $2.5 \mathrm{~km} / \mathrm{h}$. If $\mathrm{F}$ is the maximum force applied, then, the power (Equation 5) is divided by the number of motors to be used. In this case, the number of motors is 2 .

$\mathrm{P}=\mathrm{F} \times \mathrm{V}$

Total Power $\mathrm{P}=42.7 \frac{2.5 \times 1000}{3600}=29.65 \mathrm{Nm} / \mathrm{s}$

Power of 1 Motor $\frac{P}{2}=\frac{29.65}{2}=14.83 \mathrm{Nm} / \mathrm{s}=14.83 \mathrm{~W}$

\subsubsection{Calculation of torque and angular speed}

To calculate torques and angular speeds in $(r / s)$, Equation 6 and Equation 7 were applied. Here, $r$ is the wheel radius and $p$ is the engine power (Table 11).

$\omega=\frac{\mathrm{V}}{\mathrm{r}}$

$$
\begin{aligned}
& \omega=\frac{\mathrm{V}}{\mathrm{r}}=\frac{2.5 \times 1000}{3600 \times 0.065}=10.68 \mathrm{rad} / \mathrm{s} \\
& \mathrm{T}=\frac{\mathrm{P}}{\omega}
\end{aligned}
$$

$$
\mathrm{T}=\frac{\mathrm{P}}{\omega}=\frac{14.83}{10.68}=1.389 \mathrm{Nm}
$$

\subsection{Computational system development}

To establish video conferencing between remote user " $\mathrm{A}$ " and the robot, two HTML language programs were developed, one for the robot's tablet, and one for the user's tablet or computer. For each HTML program (part of the robot and user), a java language code was integrated, in order to enables video conferencing between the two sides. This code was adapted and is available from (Bistri Communication Inside, 2019). However, for the video conferencing to be possible, browsers must be web compatible to Real-Time Communications (webRTC) service. Some of the supported browsers are Google Chrome, Mozilla Firefox, and Internet Explorer.

For the robot navigation control, a java code was integrated into the user's HTML program. In this code five buttons were created, as shown in Figure 13, and they are: move left, move right, move forward, move backward and stop. Each button was associated to a fixed value that is sent to the Arduino microcontroller whenever the user presses it. These values correspond to the conditions established for robot movement (front, back, left, right, and stop).
The Arduino microcontroller was programmed to receive the user's movement conditions (values). By pushing the move forward button, for example, a value is received by the WiFi module via its IP address, and is passed to the Arduino microcontroller, which in turn directs the robot to go forward. Table 12 shows the commands sent by the user at the push of a button, and that are recognized by Arduino microcontroller. Figure 14 shows the data transmission that occurs between the user and the robot sides.

\section{Results obtained}

\subsection{Visual communication test}

In the video conferencing java codes, there are three important variables, which are "var room, var members and var localStream". Var room stores the conference name, var members stores the members that are part of the conference, while var localStrean enables real-time conferencing between the room members. The "if (! Bc.isCompatible ())" condition checks if the browser is webRTC compatible, if the browser is not compatible, then, an incompatibility message will be displayed "browser is not WebRTC compatible". To integrate this code into the developed HTML file, it was necessary to register on the Bistri website to obtain appId and appkey. All programs with the same appId and appkey are classified as "members" of

Table 11. Motor's requisites.

\begin{tabular}{|c|c|}
\hline & Minimum Value \\
\hline Power & $14.83 \mathrm{~W}$ \\
\hline Angular Velocity & $10.68 \mathrm{rad} / \mathrm{s}$ \\
\hline Torque & $1.389 \mathrm{Nm}$ \\
\hline
\end{tabular}

Table 12. Control values send to by the user.

\begin{tabular}{|c|c|c|}
\hline User Button & Value (char) & Action on Arduino \\
\hline Move Forward & 2 & Robot moves Forward \\
\hline Move Backward & 8 & Robot moves Backward \\
\hline Move Left & 4 & Robot turns Left \\
\hline Move Right & 6 & Robot turns Right \\
\hline Stop & 5 & Robot Stops \\
\hline
\end{tabular}

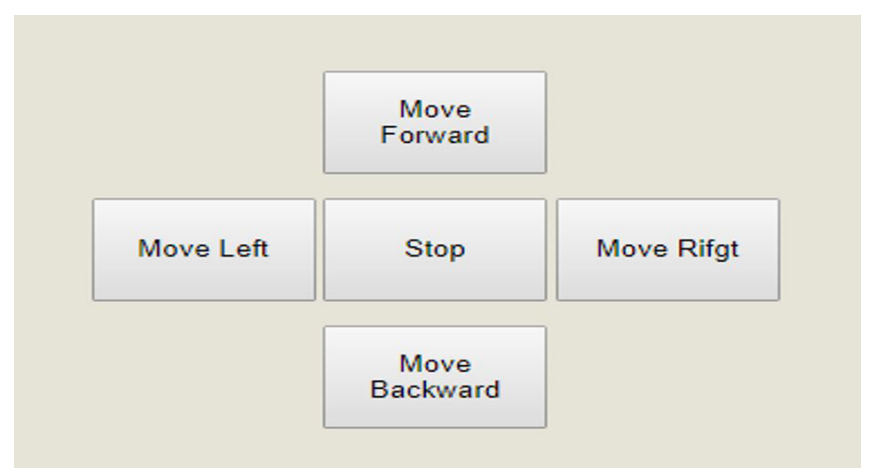

Figure 13. Navigation control keys. Source: Author. 


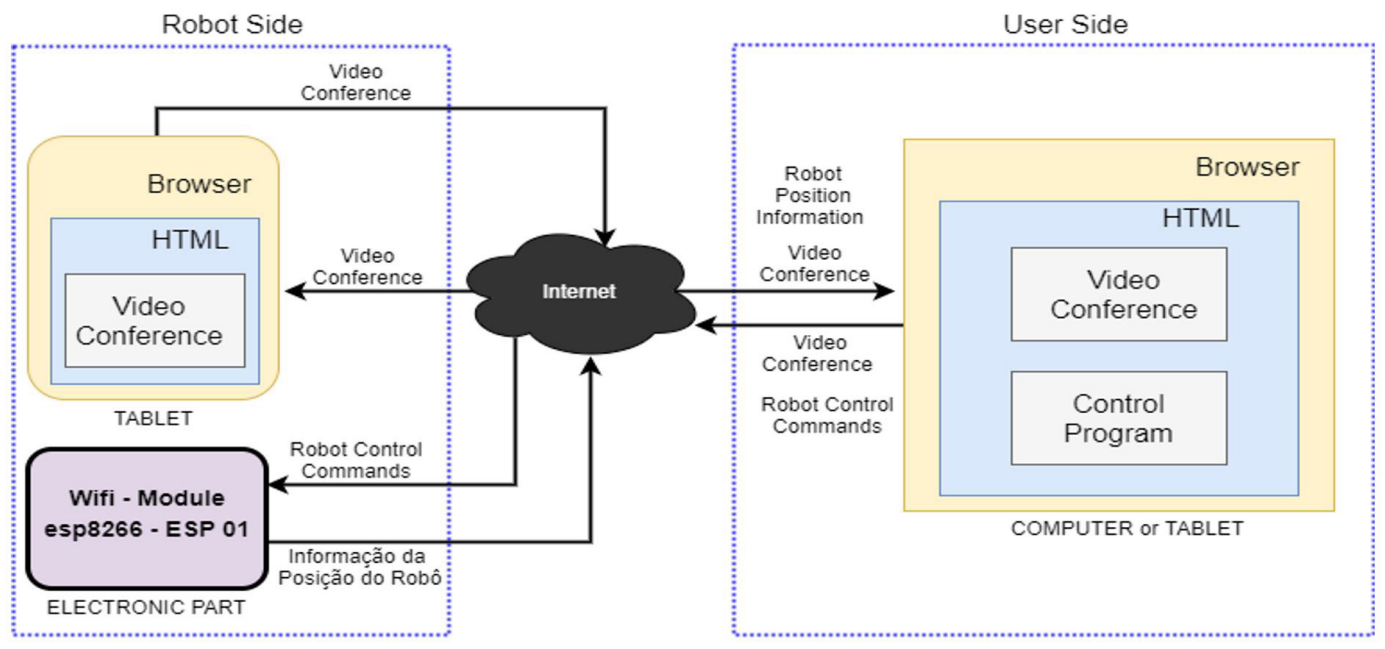

Figure 14. Data transmission between the user and the robot. Source: Author.

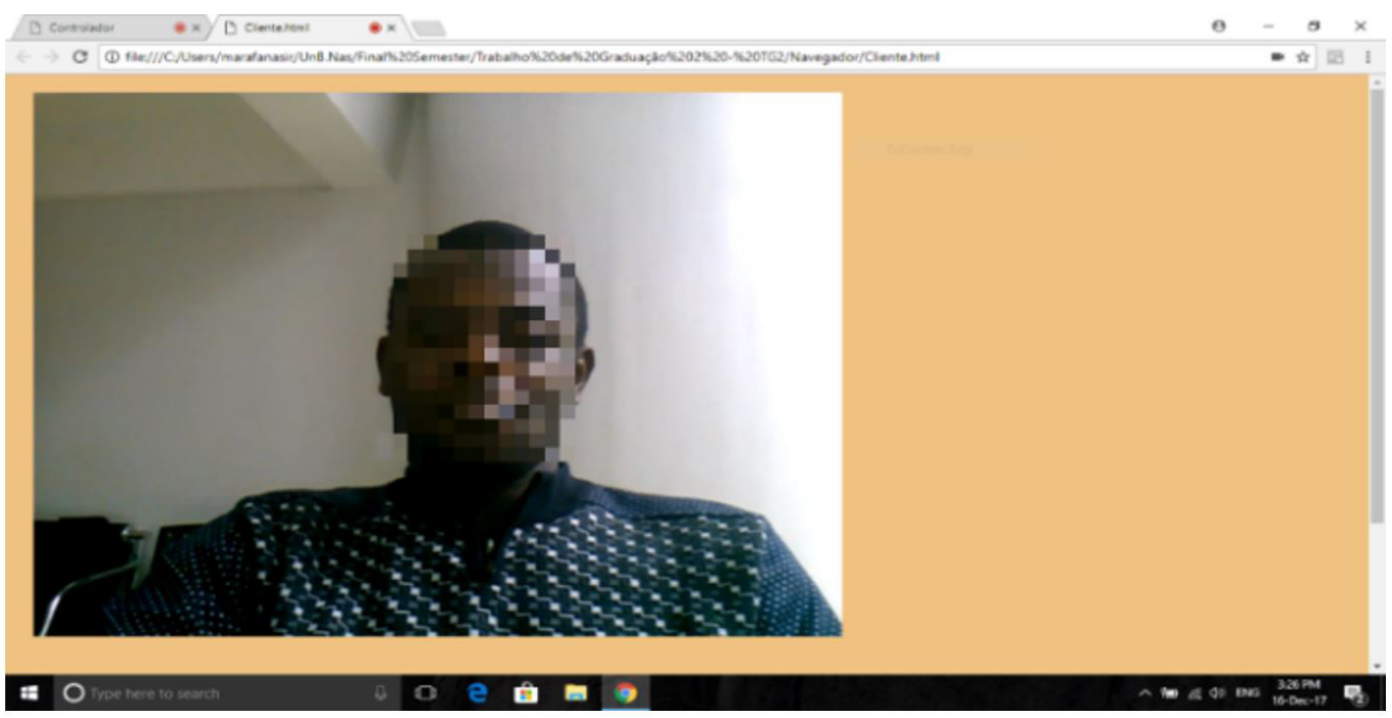

Figure 15. Video-Conferencing the Robot Side.

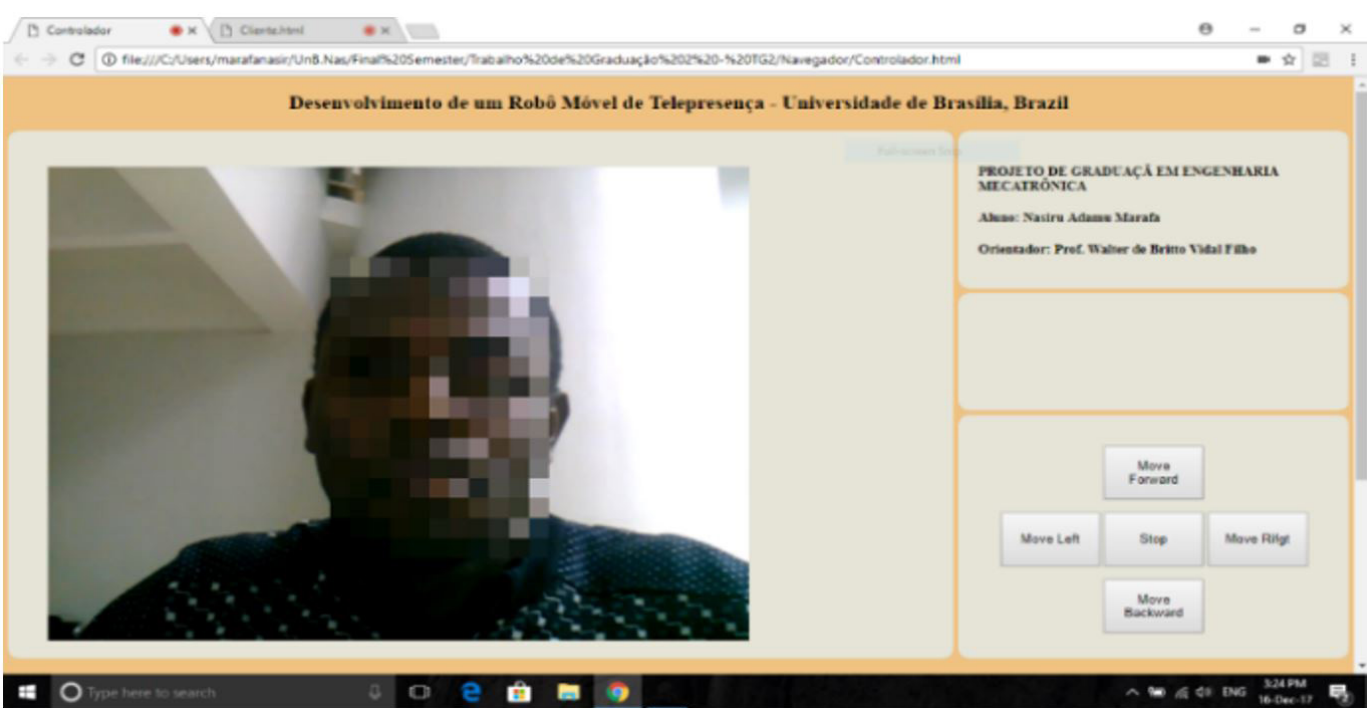

Figure 16. Video-Conferencing User Side. 


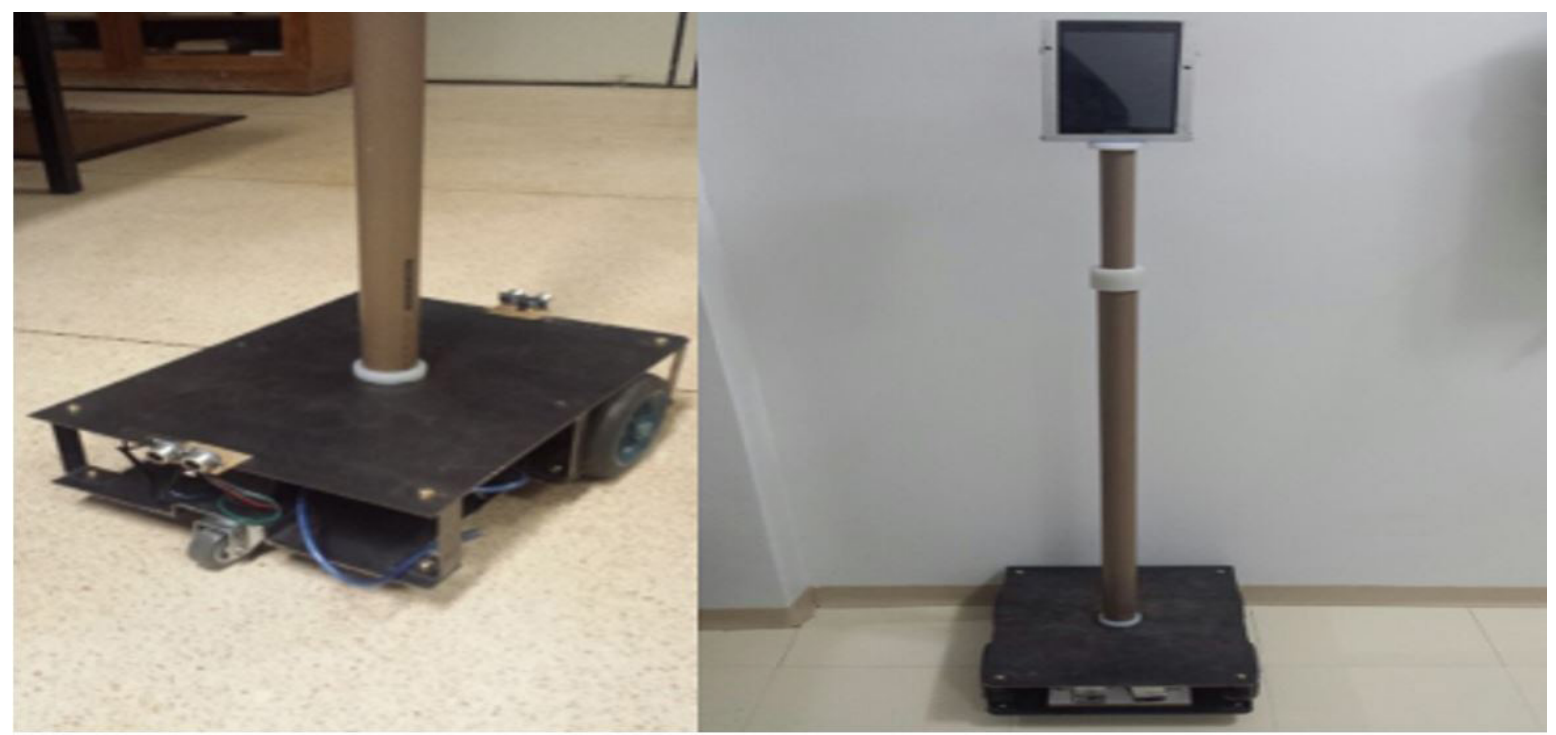

Figure 17. A Robot Prototype Construction.

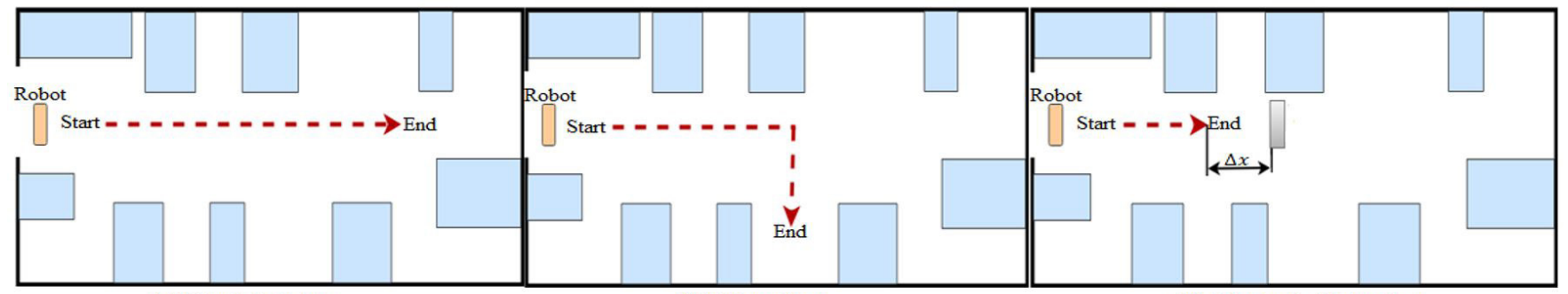

(a) Straight Line

(b) Direction

(c) Obstacle Detection

Figure 18. (a) Straight Line Test, (b) Direction Test and (c) Obstacle Detection Test.

the same room, and can have a video conference between them. In both programs (robot program and user programs), the same appId and appkey were used, making it possible to perform video conferencing between the robot and the user. Both programs were tested. Figure 15 and Figure 16 present the results of these tests.

\subsection{Robot prototype construction}

The robot's vertical structure was constructed using PVC pipe and the base with a steel plate. The electronic circuit is placed in the robot's base. Figure 17 shows the integration of the two structures, the vertical structure and the base.

\subsection{Robot motion test}

The Robot was tested in three phases as shown in Figure 18. In (a), the robot was placed to move in a straight line, where the performance of the encoders was tested. This is to ensure equal speeds on both driver wheels at a given displacement. In (b), the direction test was performed in order to verified the robot's ability to change directions by rotating left or right, in this case, the freewheel played a significant role. In (c), robot control was tested by detecting obstacles in its path, to achieve this, a minimum distance $\Delta \mathrm{x}$ between the robot and the obstacle was established. Upon reaching $\Delta \mathrm{x}$, the robot stops and waits for the next command. The forward and backward motions, acceleration and deceleration were also verified. However, for testing the ramp of $20^{\circ}$, the robot was found to climb a ramp of up to $26^{\circ}$. This might be due to the specifications of the motors used during the design. The specification of torque, power and angular velocity of the motor used are greater than the calculated.

\section{Conclusions}

In this paper, a methodology for the design and development of a mobile telepresence robot for paraplegics was presented. The design methodology is systemic, and follow a top-down approach, seeking to subdivide the project into smaller components, which are later integrated. This division not only facilitates the development, but also facilitates 3D remodeling and maintenance planning. The prototype was built in the institution's own workshop and it costed approximately USD 300.00 . This cost is an estimated cost of the final product. This cost well below the 
price of those telepresence robots available in the market for commercial gains as shown in Table 2.

It was noted that, the use of encoders helped to ensure that, both the motors have the same speed, thus, ensuring that the robot can moves in a straight line. The use of steel plates at the construction of the robot's base made the robot heavier, this also improved the robot's stability. Robot teleoperation tests via the Internet showed that network delays did not significantly affect control commands.

In the bibliometric analysis as shown in Figure 3 to 6, some of the names or words appeared blurred. This is expected, because they are being dominated by the most cleared ones. Example of this dominance is clearly seen in "Lawrence (1993)" Figures 3 and 4 and also in "Robot" Figures 5 and 6 . They appeared bigger and clearer because they dominated the others.

This work will allow further research in the area of product development for people with disabilities to integrate them into the community. It can also help in future design improvements, such as a redesign of the robot that can go up / down steps.

\section{References}

Adalgeisson, S. O., \& Breazeak, C. (2010). MeBot: a robotic platform for socially embodied telepresence. In Proceedings of the 5th ACM/IEEE International Conference on HumanRobot Interaction (pp. 15-22). ACM.

Agah, A., \& Tanie, K. (1999). Multimedia human-computer interaction for presence and exploration in a telemuseum. Presence (Cambridge, Mass.), 8(1), 104-111.

Agarwal, R., Levinson, A. W., Allaf, M., Marcov, D., Nason, A., \& Su, L. (2007). The RoboConsultant: telementoring and remote presence in the operating room during minimally invasive urologic surgeries using a novel mobile robotic interface. Urology, 70(5), 970-974.

Ballantyne, G. H. (2002). Robotic surgery, telerobotic surgery, telepresence, and telementoring: review of early clinical results. Surgical Endoscopy and Other Interventional Techniques, 16(10), 1389-1402.

Bistri Communication Inside. (2019). JavaScript for video conference. Retrieved in 2020, February 3, from https://jsfi ddle.net/bistri/SjQ6T/

Burgard, W., Cremers, A. B., Fox, D., Hähnel, D., Lakemeyer, G., Schulz, D., Steiner, W., \& Thrun, S. (1999). Experiences with an interactive museum tour-guide robot. Artificial Intelligence, 114(1-2), 3-55.

Carranza, K. A. R., Day, N. J. B., Lin, L. M. S., Ponce, A. R., Reyes, W. R. O., Abad, A. C., \& Baldovino R. G. (2019). Akibot: a telepresence robot for medical teleconsultation. In Proceedings of the 2018 IEEE 10th International Conference Humanoid, Nanotechnology, Information,
Technology, Communication and Control, Environment and Management HNICEM 2018 (pp. 1-4). IEEE.

Christopher \& Dana Reeve Foundation. (2019). Stats about paralysis: prevalence of paralysis in the United States. Retrieved in 2020, February 3, from https://www.christopherreeve.org/ living-with-paralysis/stats-about-paralysis

Coradeschi, S., Cesta, A., Cortellessa, G., Caraci, L., Gonzales, J., Karlsson, L., Furfari, F., Loutfi, A., Orlandini, A., Palumbo, F., Von Rump, S., Stimec, A., Ullberg, J., \& Otslund, B. (2013). GIRAFFPLUS: combining social interaction and long term monitoring for promoting independent living. In Proceedings of the 6th International Conference on Human System Interaction (pp. 578-585). IEEE.

Do, H. M., Mouser, C. J., Gu, Y., Sheng, W., Honarvar, S., \& Chen, T. (2013). An open platform telepresence robot with natural human interface. In IEEE 3rd Annual International Conference on Cyber Technology in Automation, Control and Intelligent Systems (CYBER) (pp. 81-86). IEEE.

Draper, J. V., Kaber, D. B., \& Usher, J. M. (1998). Telepresence. Human Factors, 40(3), 354-375.

Henry, P., Krainin, M., Herbst, E., Ren, X., \& Fox, D. (2012). RGB-D mapping: using Kinect-style depth cameras for dense 3D modeling of indoor environments. The International Journal of Robotics Research, 31(5), 647-663.

Hijazi, A., \& Al-Khatib, A. (2016). Telepresence robot. Northrop Grumman. Engineering and science student design showcase. Melbourne, FL: Florida Institute of Technology.

Hu, T., Castellanos, A. E., Tholey, G., \& Desai, J. P. (2002). Real-time haptic feedback in laparoscopic tools for use in gastro-intestinal surgery (Vol. 2488, pp. 66-74). Minnesota: The Medical Image Computing and Computer-Assisted Intervention.

Instituto Brasileiro de Geografia e Estatistica - IBGE. (2009). Sistema IBGE de Recuperação Automática-SIDRA. Rio de Janeiro: IBGE. Retrieved in 2020, January 29, from https:// sidra.ibge.gov.br/tabela/2645

Katyal, K. D., Brown, C. Y., Hechtman, S. A., Para, M. P., Mcgee, T. G., Wolfe, K. C., Murphy, R. J., Kutzer, M. D. M., Tunstel, E. W., McLoughlin, M. P., \& Johannes, M. S. (2014). Approaches to robotic teleoperation in a disaster scenario: from supervised autonomy to direct control. In Proceedings of the 2014 IEEE/RSJ International Conference on Intelligent Robots and Systems (pp. 1874-1881). IEEE.

Kristoffersson, A., Coradeschi, S., \& Loutfi, A. (2013). A review of mobile robotic telepresence. Advances in HumanComputer Interaction, 2013, 1-17.

Lailla, M., Liliane, G., \& Luiz, H. (2018). IBGE constata 6,7\% de pessoas com deficiência no Brasil com nova margem de 
corte. São Paulo: Diversa Educação Inclusiva na Prática. Retrieved in 2020, August 15, from https://diversa.org.br/ artigos/ibge-constata-67-de-pessoas-com-deficiencia-nobrasil/

Lawrence, D. A. (1993). Stability and transparency in bilateral teleoperation. IEEE Transactions on Robotics and Automation, 9(5), 624-637.

Lazewatsky, D. A., \& Smart, W. D. (2011). An inexpensive robot platform for teleoperation and experimentation. In Proceedings of the IEEE International Conference on Robotics and Automation (pp. 1211-1216). IEEE.

Ma, Z., \& Ben-Tzvi, P. (2015). RML glove - an exoskeleton glove mechanism with haptics feedback. IEEE/ASME Transactions on Mechatronics, 20(2), 641-652.

Michaud, F., Boissy, P., Labonte, D., Corriveau, H., Granty, A., Lauria, M., Cloutier, R., Roux, M. A., Lannuzzi, D., \& Roye, M. P. (2007). Telepresence robots for home care assistance. In Proceedings of the AAAI Spring Symposium Technical Report (pp 50-55). AAAI.

Michaud, F., Boissy, P., Labonte, D., Corriveau, H., Granty, A., Lauria, M., Cloutier, R., Roux, M. A., Lannuzzi, D., \& Roye, M. P. (2008). A telementoring robot for home care. Assistive Technology Research Series, 21, 138-145.

Minsky, M. (1980). Telepresence. Omni Magazine, p. 45-52. Retrieved in 2020, July 17, from http://www.housevampyr. com/training/library/books/omni/OMNI_1980_06.pdf

Moyle, W., Jones, C., Cooke, M., O’Dwyer, S., Sung, B., \& Drummond, S. (2013). Social robots helping people with dementia: assessing efficacy of social robots in the nursing home environment. In Proceedings of the 6th International Conference on Human System Interaction (pp. 608-613). IEEE.

Novaes, D. R., Miranda, A. S., \& Dourado, V. Z. (2011). Velocidade usual da marcha em brasileiros de meia idade e idosos. Brazilian Journal of Physical Therapy, 15(2), 117-122.

Pang, W. C., Seet, G., \& Yao, X. (2014). A study on highlevel autonomous navigational behaviors for telepresence applications. Presence (Cambridge, Mass.), 23(2), 155-171.

Park, N., Lee, K. M., Jin, S. A., \& Kang, S. (2010). Effects of pre-game stories on feelings of presence and evaluation of computer games. International Journal of HumanComputer Studies, 68(11), 822-833. Pfeiffer, C., Mavroids, C., Bar-Cohen, Y., \& Dolgin, B. (1999). Electroheological fluid based force feedback device. In M. R. Stein (Ed.), Proceedings of the Telemanipulator and Telepresence Technologies: Vol. 3840 (pp. 88-99). SPIE.

Pino, M., Boulay, M., Jouen, F., \& Rigaud, A. (2015). “Are we ready for robots that care for us? "Attitudes and opinions of the adults toward socially assistive robots. Frontiers in Aging Neuroscience, 7, 141.

Robots. (2020). Telepresence robots. Retrieved in 2020, February 3, from https://telepresencerobots.com/robots

Rodrigues, I. B., Vidal Filho, W. B., \& Vidal, L. F. C. S. (2015). Metodologia de desenvolvimento de robô móvel para telepresença. In Anais do VII Encontro de Ciência e Tecnologia. SBC.

Saitoh, K., Machida, T., Kiyokawa, K., \& Takemura, H. (2006). A 2D-3D integrated interface for mobile robot control using omnidirectional images and 3D geometric models. In ISMAR'06: Proceedings of the 5th IEEE and ACM International Symposium on Mixed and Augmented Reality (pp. 173-176). IEEE.

Satava, R. M. (2002). Surgical robotics: the early chronicles: a personal historical perspective. Surgical Laparoscopy, Endoscopy \& Percutaneous Techniques, 12(1), 6-16.

Schmidt, L., Hegenberg, J., \& Gramar, L. (2014). User studies on teleoperation of robots for plant inspection. Industrial robot. International Journal (Toronto, Ont.), 41(1), 6-14.

Schulz, D., Burgard, W., Fox, D., Thrun, S., \& Cremers, A. B. (2001). Web interfaces for mobile robots in public places. IEEE Robotics \& Automation Magazine, 7(1), 48-56.

Sharkey, A. J. C. (2016). Should we welcome robot teachers? Ethics and Information Technology, 18(4), 283-297.

Sucher, J. F., Todd, S. R., Jones, S. L., Throckmorton, T., Turner, K. L., \& Moore, F. A. (2011). Robotic telepresence: a helpul adjunct that is viewed favorably by critically ill surgical patients. American Journal of Surgery, 202(6), 843-847.

Tachi, S., Komoriya, K., Sawasa, K., Nishiyama, T., Itoko, T., Kobayashi, M., \& Inoue, K. (2003). Telexistence cockpit for humanoid robot control. Advanced Robotics, 17(3), 199-217.

Tanaka, F., Takahashi, T., Matsuzoe, S., Tazawa, N., \& Morita, M. (2013). Child-operated telepresence robot: a field trial connecting classrooms between australia and Japan. In Proceedings of the IEEE International Conference on Intelligent Robots and Systems (pp. 5896-5901). IEEE.

Taylor, R., Jensen, P., Whitcomb, L., Barnes, A., Kumar, R., Stoianovici, D., Gupta, P., Wang, Z. X., De Juan, E., \& Kavoussi, L. (1999). A steady-hand robotic system for microsurgical augmentation. Lecture Notes in Computer Science, 1679(12), 1031-1041. Including subseries Lecture Notes in Artificial Intelligence and Lecture Notes in Bioinformatics.

Tsui, K. M., Desai, M., Yanco, H. A., \& Uhlik, C. (2011). Exploring use cases for telepresence robots. In HRI 2011 Proceedings of the 6th ACM/IEEE International Conference 
on Human-Robot Interaction (pp. 11-18). Association for Computing Machinery.

Tsui, K. M., Nortion, A., Brooks, D. J., McCann, E., Medvedev, M. S., \& Yanco, H. A. (2013). Design and development of two generations of semi-autonomous social telepresence robots. In Proceedings of the IEEE Conference on
Technologies for Practical Robot Application (pp. 1-6). IEEE.

Yates, D., Vaessen, C., \& Roupret, M. (2011). From Leonardo to da Vinci: the history of robot-assisted surgery in urology. BJU International, 108(11), 1708-1713. 